City University of New York (CUNY)

CUNY Academic Works

2014

\title{
Is burnout a depressive disorder? A reexamination with special focus on atypical depression
}

\author{
Renzo Bianchi \\ Université de Neuchâtel \\ Irvin Sam Schonfeld \\ cUNY Graduate Center \\ Eric Laurent \\ Université de Franche-Comté
}

\section{How does access to this work benefit you? Let us know!}

More information about this work at: https://academicworks.cuny.edu/cc_pubs/299

Discover additional works at: https://academicworks.cuny.edu

This work is made publicly available by the City University of New York (CUNY).

Contact: AcademicWorks@cuny.edu 


\title{
Is Burnout a Depressive Disorder? A Reexamination With Special Focus on Atypical Depression
}

\author{
Renzo Bianchi \\ University of Franche-Comté \\ Irvin Sam Schonfeld \\ The City College of the City University of New York \\ Eric Laurent \\ University of Franche-Comté
}

Whether burnout and depression cover the same psychopathology remains to be elucidated. To date, subtypes of depression have been overlooked in research on the burnout-depression overlap. Our aim was to estimate the prevalence of depressive disorders in workers with burnout while examining the overlap of burnout with the atypical subtype of depression. The present study included 5,575 schoolteachers (mean age $=41$ years; $78 \%$ female). Burnout was assessed with the Maslach Burnout Inventory. Depression was measured with the 9-item depression scale of the Patient Health Questionnaire (PHQ-9). Atypical features of depression were examined using a dedicated module, referenced to the Diagnostic and Statistical Manual of Mental Disorders (4th ed.; American Psychiatric Association, 1994). We found that $90 \%$ of the teachers identified as burned out met diagnostic criteria for depression. Among them, 92\% scored 15 or higher on the PHQ-9, a threshold at which active treatment with pharmacotherapy and/or psychotherapy is recommended. The features of atypical depression were observed in $63 \%$ of the burned-out participants with major depression. Emotional exhaustion, the hallmark of burnout, was more strongly associated with depression than with depersonalization and reduced personal accomplishment, the 2 other putative dimensions of burnout. The present study suggests

This article was published Online First September 15, 2014.

Renzo Bianchi, Department of Psychology, University of Franche-Comté; Irvin Sam Schonfeld, Department of Psychology, The City College of the City University of New York; Eric Laurent, Department of Psychology, University of Franche-Comté.

Correspondence concerning this article should be addressed to Renzo Bianchi, Laboratoire de Psychologie EA 3188, Université de Franche-Comté, 30-32 rue Mégevand, 25030 Besançon CEDEX, France. E-mail: renzo.bianchi@univ-fcomte.fr 
that the burnout-depression overlap has been largely underestimated. Atypical depression may account for a substantial part of this overlap. Overall, our findings point to depressive symptoms and depressive disorders as central concerns in the management of burnout. The clinical research on treatments for depression offers solutions that may help workers identified as burned out.

Keywords: atypical depression, burnout, depression, depressive disorder spectrum, occupational stress

Burnout is usually regarded as a work-related chronic stress syndrome combining emotional exhaustion, depersonalization, and reduced personal accomplishment (Maslach, Schaufeli, \& Leiter, 2001; Schaufeli \& Enzmann, 1998). Emotional exhaustion refers to the feelings of being emotionally drained and overextended. Energy is lacking and low mood prevails. Depersonalization characterizes a distant and callous attitude toward one's job and the people connected to it (e.g., students, patients, clients). The worker shows weakened motivation and withdraws from an occupation that once sustained a great deal more interest for him or her. Lastly, reduced personal accomplishment includes feelings of inadequacy and incompetence associated with loss of self-confidence. This third dimension, however, was not present in the original working definition of burnout and its belonging to the burnout syndrome is doubtful (Hakanen \& Schaufeli, 2012; Schaufeli \& Taris, 2005). Characterized as "a crisis in one's relationship with work" (Maslach, Jackson, \& Leiter, 1996, p. 20), the state of burnout has been viewed as "a final stage in a breakdown in adaptation" (Schaufeli \& Buunk, 2004, p. 389), and contrasts with transient, nonmorbid job stress. Although the prevalence of burnout, strictly speaking, is currently unknown, burnout is considered a serious occupational health problem (Schaufeli \& Buunk, 2004; Schaufeli \& Enzmann, 1998).

Depression is primarily defined by two core symptoms: anhedonia (i.e., markedly diminished interest or pleasure in most activities) and depressed mood (American Psychiatric Association [APA], 1994; Sapolsky, 2004). Depression has been investigated both in its clinical and subclinical forms and scrutinized in various contexts, including the occupational context (e.g., Kahn, 2008; Rydmark et al., 2006). Stress plays a central role in the etiology of depression as in the etiology of burnout (Sapolsky, 2004; Tennant, 2001). The sustained impossibility of controlling one's environment and actively neutralizing stressors is a key etiological factor in many theories of depression (Gilbert, 2006; C. Peterson, Maier, \& Seligman, 1993). Depression has been ranked by the World Health Organization as the single most burdensome disease in the world in terms of total disability-adjusted life years among people in midlife (see Gotlib \& Hammen, 2009). 
Whether the state of burnout should be considered a form of depression or a distinct entity remains an object of controversy (Bianchi, Boffy, Hingray, Truchot, \& Laurent, 2013; Hallsten, 1993; Taris, 2006). Although there is some evidence that burnout and depression can be empirically distinguished (Maslach et al., 2001), the two syndromes, from a clinical standpoint, tend to overlap at both an etiological level-with unresolvable stress as the nodal contributory factor-(Hätinen, Kinnunen, Pekkonen, \& Kalimo, 2007; McEwen, 2004; Rydmark et al., 2006) and a symptom level (Bianchi et al., 2013; Kahn, 2008). Freudenberger (1974), one of the earliest authors to identify the burnout concept in print, already observed that the burned-out person "looks, acts and seems depressed" (p. 161).

More specifically, burnout shares key features with atypical depression (APA, 1994; Quitkin, 2002), a frequently met subtype of depression that is, inter alia, characterized by mood reactivity (mood brightens in response to actual or potential positive events); interpersonal rejection sensitivity, resulting in significant social or occupational impairment; and hypocortisolism, a biological marker of altered functioning of the hypothalamic-pituitaryadrenocortical (HPA), or "stress," axis (APA, 1994; Gold \& Chrousos, 2002; Tops, Riese, Oldehinkel, Rijsdijk, \& Ormel, 2008). Despite intriguing similarities, the overlap of burnout and atypical depression has never been investigated in a systematic manner.

It has been advanced that burnout can be discriminated from other mental disorders, and, in particular, that burnout and depression are separate nosological entities (Iacovides, Fountoulakis, Kaprinis, \& Kaprinis, 2003; Schaufeli, 2003), but research supporting these views is sparse. To date, only one study (Ahola et al., 2005) has been expressly designed to determine whether workers with burnout meet the diagnostic criteria for depression as defined in the Diagnostic and Statistical Manual of Mental Disorders (4th ed.; DSM-IV; APA, 1994). The results of Ahola et al.'s (2005) study indicated that about $53 \%$ of the individuals with so-called severe burnout presented with a depressive disorder, pointing to important, yet limited, overlap between burnout and depression. However, the clinical significance of these results has been questioned (Bianchi et al., 2013), given the relatively liberal cutoff score chosen for identifying individuals suffering from severe burnout-3.5/6.0 on the Maslach Burnout Inventory (MBI)-General Survey. Indeed, this cutpoint was lower than generally recommended (Maslach et al., 1996; Schaufeli \& Enzmann, 1998), and hence implied a high risk of false-positive inclusion. Recently, Bianchi et al. (2013), using more conservative cutoff scores for defining cases of burnout, found no diagnostically significant difference between burned-out workers and depressed outpatients in terms of reported depressive symptoms. The authors suggested that burnout and depression may, in fact, reflect the same psychopathology. 
In sum, the extent to which burnout and depression represent overlapping syndromes remains ill-understood.

This state of affairs is problematic for the management of burnout. Without a clear characterization of the syndrome, calibrating effective intervention strategies is challenging. For instance, depending on whether burnout is primarily characterized as a fatigue or a depressive syndrome, different measures should be taken. The burnout construct cannot be helpful in terms of public health and organizational policies if we are unable to clearly specify what burnout actually is (diagnosis) and, relatedly, the extent to which burnout differs from existing diagnoses such as depression (differential diagnosis). Importantly, if the state of burnout is associated with a depressive clinical picture, trying to separate it from the spectrum of depressive disorders may be a source of confusion, rather than of clarity, for both clinicians and researchers.

The aim of the present study was to estimate the prevalence of depressive disorders in workers with burnout while examining the overlap of burnout with atypical depression. We used a conservative cutoff score for identifying burned-out workers in order to limit the number of false positives among them. Given the apparent affective (e.g., mood reactivity) and neuroendocrine (e.g., hypocortisolism) similarities of burnout and atypical depression, we hypothesized substantial overlap of the two conditions. Because the depressive disorder spectrum is heterogeneous (e.g., Gold \& Chrousos, 2002), questioning the overlap of burnout with specific depression subtypes is indispensable to understanding what it means to be burned out. Burnout and depression can be conceptualized either dimensionally or categorically (Ingram \& Siegle, 2009; Schaufeli, 2003). By virtue of its clinical relevance, a primarily categorical approach to burnout and depression was adopted in this study. Clarifying burnout's nosological status is an important component of efforts to evaluate the utility of the construct in terms of preventive and clinical interventions. Because the use of the burnout label has been shown to increase the risk of leaving depressive disorders untreated (Bahlmann, Angermeyer, \& Schomerus, 2013), it is a major concern that we determine whether the burnout label is nosologically justified. The current use of the burnout label may conceal an unnoticeably high — and possibly risingprevalence of depression in the workplace (Bahlmann et al., 2013; Tennant, 2001).

\section{METHOD}

The MBI (Maslach et al., 1996), the nine-item depression module of the Patient Health Questionnaire (PHQ-9; Kroenke \& Spitzer, 2002; 
Kroenke, Spitzer, \& Williams, 2001), and a sociodemographic and health form were e-mailed to several thousand elementary, middle, and high schools in France by using academic databases. Participant recruitment was carried out during the April to June and November to December periods in 2012. Being a teacher was the only eligibility criterion for participating in the study. A total of 5,575 teachers completed the questionnaires (mean age [range]: 41 years [22 to 65]; $78 \%$ female). Past research has shown that Internet questionnaires are as valid and reliable as traditional paper-andpencil questionnaires (Gosling, Vazire, Srivastava, \& John, 2004; Jones, Fernyhough, de-Wit, \& Meins, 2008; Ritter, Lorig, Laurent, \& Matthews, 2004). We note that we conducted an analytic rather than a descriptive study (see Kristensen, 1995). Our study's aim was not to determine the prevalence of burnout and depression in the (French) schoolteacher population, but to ascertain the extent to which a worker could be burned out without being simultaneously depressed; therefore, sample representativeness was not a concern for us here. Participants interested in being informed of the survey's outcomes had the possibility of communicating their e-mail address to the authors. Full confidentiality was ensured to all participants.

\section{MBI}

The MBI is a 22-item questionnaire that measures burnout and its three components: emotional exhaustion, depersonalization, and reduced personal accomplishment. Each item employs a 7-point frequency scale (from 0 for never to 6 for everyday). Depending on research objectives, burnout dimensions can be considered either separately or combined to yield a global burnout score (Ahola et al., 2005; Brenninkmeijer \& van Yperen, 2003). The choice of a global score was made in this study, given our focus on burnout as a unified entity. In line with most recent developments in burnout research, we did not use the reduced personal accomplishment dimension when computing this global score because of serious doubts regarding that dimension's belonging to the burnout syndrome (Hakanen \& Schaufeli, 2012; Schaufeli \& Taris, 2005). Finally, we attributed different weights to emotional exhaustion and depersonalization in our global burnout score $(0.6 \times$ emotional exhaustion $+0.4 \times$ depersonalization), in view of the primacy of emotional exhaustion in burnout (Maslach et al., 2001; Schaufeli \& Enzmann, 1998). Similar weighting procedures have been used in the past to take into account the specific link of each burnout dimension to individual health outcomes (e.g., Ahola et al., 2005). In this study, Cronbach's alphas were .89 for emotional exhaustion, .68 for depersonalization, and .88 for the two dimensions combined. 
To be assigned to the burnout group, a participant had to exhibit an MBI mean score of at least 5 . Such a score indicates that burnout symptoms are experienced several times a week. A sample of 67 participants (1\%) met this inclusion criterion. Their mean age was 45 years $(S D=9)$ and their mean length of employment was 19 years $(S D=11)$. About $76 \%(n=51)$ of these participants were female. By opting for a cutpoint of 5, our aim was to (a) closely adhere to the MBI-related definition of burnout, which stipulates that a worker in a state of burnout is "constantly overwhelmed, stressed and exhausted" (Leiter \& Maslach, 2005, p. 2); and (b) favor the specificity of the MBI (as opposed to its sensitivity), that is, minimize the risk of including false positives among participants identified as burned out (Schaufeli \& Enzmann, 1998). In the burnout group, the mean MBI score was $5.34(S D=$ $0.24)$, the mean emotional exhaustion score was $5.60(S D=0.31)$, and the mean depersonalization score was $4.94(S D=0.54)$.

The no-burnout group consisted of the 750 participants (13\%) exhibiting an MBI mean score of, at most, 1 . The mean age in the no-burnout group was 42 years $(S D=9)$ and the mean length of employment was 16 years $(S D=10)$. About $74 \%(n=557)$ of the participants were female. The burnout and no-burnout groups did not differ in gender, $p>.70$, but differed in age, $p<.01$, and length of employment, $p<.05$, with burned-out teachers, on average, 3 years older and employed 3 years longer. A cutoff score of 1 indicates that burnout symptoms are either never experienced or experienced only a few times a year. This cutpoint is the polar opposite of the one that we used for isolating burnout cases. By relying on polar cutoff scores, our objective was to study truly burned-out participants, on the one hand, and participants who were clearly burnout-free, on the other. In the no-burnout group, the mean MBI score was $0.65(S D=0.24)$, the mean emotional exhaustion score was $0.81(S D=0.36)$, and the mean depersonalization score was $0.42(S D=0.40)$. In ancillary analyses, we altered the aforementioned criteria for identifying burnout (i.e., lowered the cutoff, used all three MBI scales, computed unweighted burnout scores) to observe how changes in burnout's definition affected the results as they bear on our research hypotheses.

\section{PHQ-9}

The PHQ-9 is a dual-purpose instrument that, with nine DSM-IVreferenced items, can establish provisional depressive disorder diagnoses and grade depressive symptom severity (Kroenke \& Spitzer, 2002). Each item is associated with a 4-point frequency scale (from 0 for not at all to 3 for nearly every day). Major depression is diagnosed if five or more of the nine DSM-IV criteria have been present at least "more than half the days" during the past 
2 weeks and if one of the symptoms is anhedonia or depressed mood (APA, 1994; Kroenke \& Spitzer, 2002). One of the nine diagnostic criteria ("Thoughts that you would be better off dead or of hurting yourself in some way.") counts if present at all, regardless of duration (Kroenke \& Spitzer, 2002). Cutpoints of 5, 10, 15, and 20 represent the thresholds for mild, moderate, moderately severe, and severe depression, respectively (Kroenke \& Spitzer, 2002). The administration of the PHQ-9 to a sample of 3,000 primary care patients revealed (a) a sensitivity going from $86 \%$ with a cutpoint of 15 , to more than $99 \%$ with a cutpoint of 10 ; and (b) a specificity going from $91 \%$ with a cutpoint of 10 , to more than $99 \%$ with a cutpoint of 15 (Kroenke \& Spitzer, 2002). The psychometric properties of the PHQ-9 make it an efficient tool for identifying major depression. A diagnosis of minor depression/depression not otherwise specified requires meeting two to four criteria, including either anhedonia or depressed mood (APA, 1994). The PHQ-9 includes an additional item providing an index of general, functional impairment ("How difficult have these problems made it for you to do your work, take care of things at home, or get along with other people?"). Cronbach's alpha for the PHQ-9 was .84 in the present study.

\section{Atypical Depression and Other Measures}

A sociodemographic and health form included questions about gender, age, lifetime history of depressive disorders, current intake of antidepressants, length of employment, and a module dedicated to the detection of atypical features of depression. The module assessed the presence of mood reactivity, significant weight gain or hyperphagia, hypersomnia, leaden paralysis (i.e., feelings of heaviness in arms and/or legs), and interpersonal rejection sensitivity resulting in social or occupational impairment (APA, 1994). To meet criteria for a diagnosis of atypical depression, an individual must show mood reactivity and at least two of four of the remaining symptoms. The diagnosis of atypical depression refines an initial diagnosis of major depression (APA, 1994). Therefore, we investigated the presence of atypical depression only in participants who met DSM-IV (APA, 1994) diagnostic criteria for major depression.

\section{RESULTS}

In the full teacher sample $(n=5,575)$, a positive correlation was found between MBI and PHQ-9 scores, $r=.68, p<.001$. Once corrected for attenuation, this correlation coefficient reached .79. Correlations between 
Table 1. Correlation Matrix Involving Emotional Exhaustion, Depersonalization, Reduced Personal Accomplishment, and Depression $(N=5,575)$

\begin{tabular}{lccc}
\hline & DP & RPA & Depression \\
\hline EE & .53 & .35 & .72 \\
DP & - & .40 & .40 \\
RPA & & - & .34 \\
\hline
\end{tabular}

Note. All correlations are significant at $p<.001 . \mathrm{DP}=$ depersonalization; $\mathrm{RPA}=$ reduced personal accomplishment; EE = emotional exhaustion.

emotional exhaustion, depersonalization, reduced personal accomplishment, and depression are presented in Table 1. Emotional exhaustion was more strongly related to depression $(r=.72)$ than to depersonalization $(r=.53)$ or reduced personal accomplishment $(r=.35), p$ s $<.001$.

Lifetime history of depression was reported by about $63 \%(n=42)$ of the teachers with burnout and $15 \%(n=114)$ of the burnout-free teachers, $p<.001$ (see Table 2). About 30\% $(n=20)$ of the burned-out participants indicated that they were currently taking antidepressant medication, compared with $4 \%(n=29)$ in the no-burnout group, $p<.001$ (see Table 2).

About $90 \%(n=60)$ of the participants in the burnout group met diagnostic criteria for depression (see Table 2), mainly for major depression (85\%). By contrast, only 3\% $(n=19)$ of the participants in the no-burnout group were identified as depressed (see Table 2), mainly with minor depression or depression not otherwise specified (2\%). Furthermore, about 92\%

Table 2. Depressive Symptoms, Depressive Disorders, Antidepressant Intake, and History of Depression as a Function of Group (No-Burnout Versus Burnout)

\begin{tabular}{|c|c|c|c|c|c|}
\hline & \multicolumn{2}{|c|}{$\begin{array}{l}\text { No-burnout } \\
\text { group }(n=750)\end{array}$} & \multicolumn{2}{|c|}{$\begin{array}{l}\text { Burnout group } \\
\quad(n=67)\end{array}$} & \multirow[b]{2}{*}{$p^{\mathrm{a}}$} \\
\hline & $M$ & $S D$ & $M$ & $S D$ & \\
\hline PHQ-9 & 3.33 & 2.90 & 19.18 & 4.22 & $<.001$ \\
\hline Anhedonia & 0.34 & 0.61 & 2.54 & 0.68 & $<.001$ \\
\hline Depressed mood & 0.26 & 0.49 & 2.24 & 0.84 & $<.001$ \\
\hline Altered sleep & 0.70 & 0.84 & 2.45 & 0.82 & $<.001$ \\
\hline Fatigue & 0.83 & 0.65 & 2.67 & 0.56 & $<.001$ \\
\hline Altered appetite & 0.49 & 0.75 & 2.43 & 0.94 & $<.001$ \\
\hline Guilt and self-blame & 0.29 & 0.52 & 2.25 & 0.86 & $<.001$ \\
\hline Cognitive impairment & 0.27 & 0.50 & 1.97 & 0.97 & $<.001$ \\
\hline Psychomotor alteration & 0.12 & 0.36 & 1.57 & 1.02 & $<.001$ \\
\hline \multirow[t]{2}{*}{ Suicidal ideation } & 0.05 & 0.26 & 1.06 & 1.11 & $<.001$ \\
\hline & \multicolumn{2}{|c|}{$\%(n)$} & \multicolumn{2}{|c|}{$\%(n)$} & $p$ \\
\hline Depressed participants & \multicolumn{2}{|c|}{$3(19)$} & \multicolumn{2}{|c|}{$90(60)$} & $<.001$ \\
\hline Participants taking AD & \multirow{2}{*}{\multicolumn{2}{|c|}{$\begin{array}{c}4(29) \\
15(114)\end{array}$}} & \multicolumn{2}{|c|}{$30(20)$} & $<.001$ \\
\hline Participants with HD & & & \multicolumn{2}{|c|}{$63(42)$} & $<.001$ \\
\hline
\end{tabular}

Note. PHQ-9 $=$ Patient Health Questionnaire 9-item module; $\mathrm{AD}=$ antidepressant medication; HD = history of depressive disorders.

${ }^{\text {a }}$ All effects remained significant after controlling for age. 
$(n=55)$ of the burned-out participants who met diagnostic criteria for depression produced scores of at least 15 on the PHQ-9, a threshold at which pharmacologic and/or psychotherapeutic treatment is recommended (Kroenke \& Spitzer, 2002; Kroenke et al., 2001). Of the burned-out teachers with depression, about $70 \%(n=42)$ declared that their depressive symptoms made their daily lives very or extremely difficult and about $60 \%$ experienced suicidal ideation $(n=36)$. No burned-out teacher was free of depressive symptoms, that is, exhibited scores less than 5 on the PHQ-9 (Kroenke \& Spitzer, 2002; Kroenke et al., 2001). About 63\% $(n=36)$ of the burned-out teachers with major depression met the criteria for atypical depression.

We conducted an analysis of variance to examine, across the entire sample, the relation of the levels of depression (minimal, mild, moderate, moderately severe, and severe), as indexed by PHQ-9 scores, to burnout symptoms, as indexed by MBI scores, $F(4,5570)=1047.83, p<.001, \eta_{\mathrm{p}}^{2}=$ 0.43 . Tukey's post hoc test revealed that all groups were distinct from each other, $p s<.001$, with every increment in the severity of depression being accompanied by a stepwise, monotonic increase in burnout symptoms (see Figure 1).

For comparative purposes, we computed the percentages of depressed participants among burned-out teachers by using four different cutoff scores (see Table 3).

To rule out the possibility that our definition of burnout may have been biased toward supporting the hypothesis being tested, we repeated the main analyses in two additional ways. First, we identified teachers who were burned out by using an unweighted combination of emotional exhaustion and depersonalization (see Table 4). Second, we combined the three dimensions of the MBI-emotional exhaustion, depersonalization, and reduced personal accomplishment - to identify burned-out teachers (see Table 5). We limited our complementary analyses to (a) estimating depression prevalence, and (b) computing MBI and PHQ-9 mean scores among burned-out participants. The findings in Tables 4 and 5 closely parallel the findings shown in Table 3, underlining the close connection of burnout with depression.

\section{DISCUSSION}

In the present study, individuals identified as burned out without meeting diagnostic criteria for depression were exceedingly rare. Indeed, about nine of 10 teachers experiencing burnout received a provisional diagnosis of depression. Based on a case-defining MBI score of 5, the prevalence of depression was similarly high regardless of whether we identified burned-out teachers using (a) weighted or unweighted burnout scores, or (b) two or three 


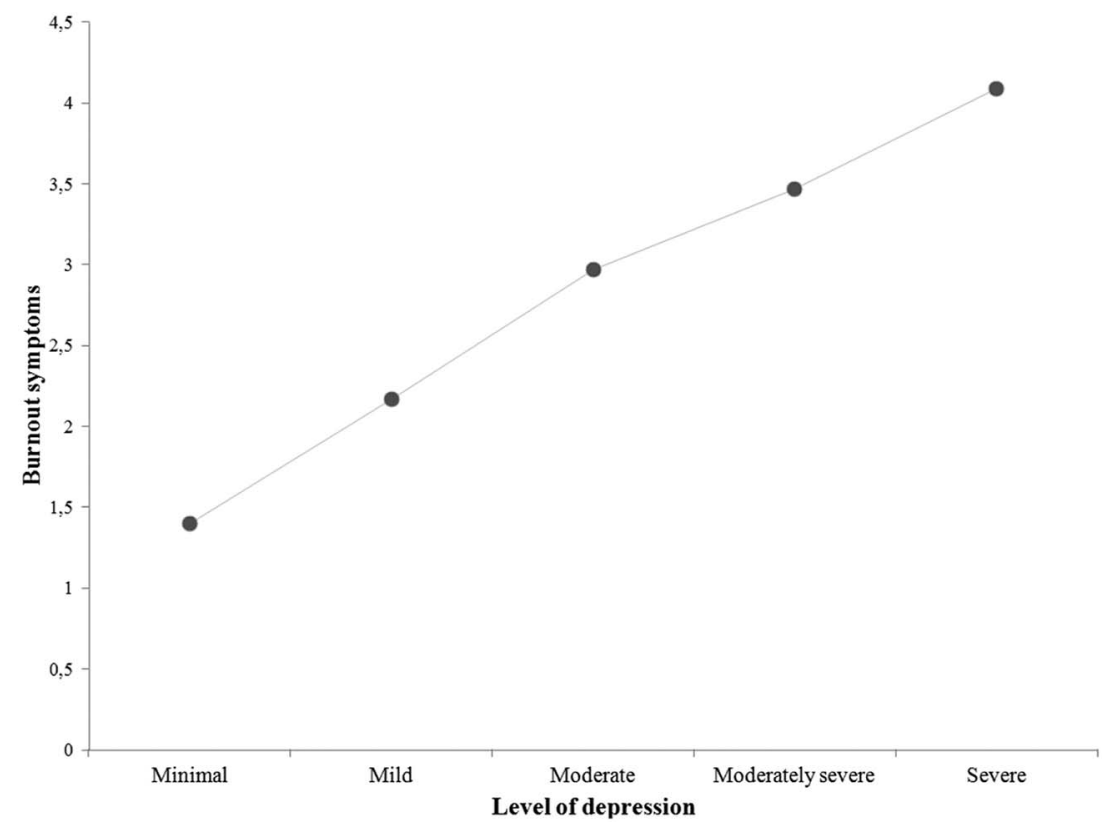

Figure 1. Burnout symptoms (assessed with the Maslach Burnout Inventory) as a function of the level of depression (assessed with the nine-item depression module of the Patient Health Questionnaire [PHQ-9]). Scores of 5, 10, 15, and 20 on the PHQ-9 represent the thresholds for mild, moderate, moderately severe, and severe depression, respectively (Kroenke \& Spitzer, 2002).

burnout dimensions (Tables 4 and 5). Our results are consistent with recent findings showing that burnout cannot be distinguished from clinical depression in terms of reported depressive symptoms (Bianchi et al., 2013). In line with previous research (e.g., Rössler, Hengartner, Ajdacic-Gross, \& Angst, in press), our results on the self-reported history of depression indicated a considerably higher lifetime prevalence of depressive disorders in the burned-out teachers compared with their burnout-free counterparts (see Table

Table 3. Ancillary Analyses Involving Four Different Cutpoints for Defining Cases of Burnout and Weighted Burnout Scores Based on Two Subscales of the MBI (Emotional Exhaustion and Depersonalization)

\begin{tabular}{lcccc}
\hline & \multicolumn{4}{c}{ Cutoff scores defining cases of burnout } \\
\cline { 2 - 5 } & $3.5(n=871)$ & $4.0(n=474)$ & $4.5(n=209)$ & $5.0(n=67)$ \\
\hline \% Depressed participants $(n)$ & $62(540)$ & $71(337)$ & $79(165)$ & $90(60)$ \\
MBI mean score $(S D)$ & $4.16(0.52)$ & $4.53(0.43)$ & $4.91(0.34)$ & $5.34(0.24)$ \\
PHQ-9 mean score $(S D)$ & $13.89(5.16)$ & $15.16(5.15)$ & $16.74(4.89)$ & $19.18(4.22)$ \\
\hline
\end{tabular}

Note. $\quad$ MBI = Maslach Burnout Inventory; PHQ-9 = Patient Health Questionnaire 9-item module. 
Table 4. Ancillary Analyses Involving Four Different Cutpoints For Defining Cases of Burnout and Unweighted Burnout Scores Based on Two Subscales of the MBI (Emotional Exhaustion and Depersonalization)

\begin{tabular}{lcccc}
\hline & \multicolumn{3}{c}{ Cutoff scores defining cases of burnout } \\
\cline { 2 - 5 } & $3.5(n=763)$ & $4.0(n=407)$ & $4.5(n=183)$ & $5.0(n=58)$ \\
\hline \% Depressed participants $(n)$ & $63(481)$ & $72(293)$ & $78(143)$ & $88(51)$ \\
MBI mean score $(S D)$ & $4.15(0.51)$ & $4.53(0.42)$ & $4.90(0.35)$ & $5.32(0.26)$ \\
PHQ-9 mean score $(S D)$ & $13.88(5.25)$ & $15.11(5.18)$ & $16.50(4.96)$ & $19.00(4.31)$ \\
\hline
\end{tabular}

Note. $\quad$ MBI $=$ Maslach Burnout Inventory; PHQ-9 = Patient Health Questionnaire 9-item module.

2). Of the teachers with burnout, $30 \%$ reported that they were currently taking antidepressants (see Table 2), confirming the use of these drugs in the treatment of burnout (Ahola et al., 2007). Finally, about $60 \%$ of the burnedout teachers identified as depressed experienced suicidal ideation, a proportion which is similar to those observed in patients with major depression (e.g., Sokero et al., 2003). Overall, our findings point to depressive symptoms - including the most extreme (e.g., suicidal thoughts) — and depressive disorders as priority concerns in the management of chronic occupational stress and burnout.

Our study revealed that a substantial fraction of teachers identified as being both burned out and depressed manifest the features of atypical depression. This finding suggests that, for many individuals, burnout and atypical depression are the same disorder, as inferred from apparent similarities in (a) mood reactivity (burned-out individuals have been found to possess some residual ability to enjoy things; Brenninkmeyer, van Yperen, \& Buunk, 2001); (b) sensitivity to interpersonal rejection, which can be viewed as the other side of depersonalization - the more an individual feels rejected, the more (s)he becomes detached-; and (c) hypocortisolism, denoting

Table 5. Ancillary Analyses Involving Four Different Cutpoints for Defining Cases of Burnout and Unweighted Burnout Scores Based on the Three Subscales of the MBI (Emotional Exhaustion, Depersonalization, and Reduced Personal Accomplishment)

\begin{tabular}{lcccc}
\hline & \multicolumn{4}{c}{ Cutoff scores defining cases of burnout } \\
\cline { 2 - 5 } & $3.5(n=520)$ & $4.0(n=212)$ & $4.5(n=67)$ & $5.0(n=15)$ \\
\hline \% Depressed participants $(n)$ & $73(380)$ & $83(176)$ & $87(58)$ & $87(13)$ \\
MBI mean score $(S D)$ & $3.99(0.40)$ & $4.37(0.34)$ & $4.80(0.25)$ & $5.18(0.19)$ \\
PHQ-9 mean score $(S D)$ & $14.74(5.20)$ & $16.25(4.97)$ & $18.51(4.52)$ & $19.00(4.57)$ \\
\hline
\end{tabular}

Note. $\quad$ MBI = Maslach Burnout Inventory; PHQ-9 = Patient Health Questionnaire 9-item module. 
altered functioning of the HPA axis regulating the stress response (Gold \& Chrousos, 2002; Tops et al., 2007). In support of this hypothesis, the fatigue symptoms and syndrome chronicity that are central in burnout have also been described as key characteristics of atypical depression (APA, 1994; Quitkin, 2002; Shirom, 2005). At a more general level, our results confirm that atypical depression is a common subtype of depression (Nierenberg, Alpert, Pava, Rosenbaum, \& Fava, 1998; Quitkin, 2002). To the best of our knowledge, the present study was the first to empirically evaluate the overlap of burnout with atypical depression.

Considering the entire sample $(N=5,575)$, we observed moderate to high correlations between burnout and depression measures, consistent with what is generally reported (Iacovides et al., 2003). Interestingly, emotional exhaustion — the core of burnout (Maslach et al., 2001) — was more strongly related to depression than to depersonalization, the second dimension of burnout (for similar results, see Bianchi et al., 2013, and Hakanen \& Schaufeli, 2012). This pattern of results underlines the ambiguous conceptual status of burnout as operationalized in the MBI (Shirom \& Melamed, 2006; Winwood \& Winefield, 2004). Once again, the relevance of the dimensions that have been selected for the elaboration of the MBI is in question (see Kristensen, Borritz, Villadsen, \& Christensen, 2005, and Schaufeli \& Taris, 2005). A syndrome, as commonly used in most areas of psychology, refers to a group of signs and symptoms that occur together and characterize a particular abnormality (Shirom, 2005). Based on such results, it is unclear why depersonalization should be considered a more cardinal feature of burnout than "classical" depressive symptoms. It is noteworthy that this issue is not limited to the MBI. In a study by U. Peterson et al. (2008), the exhaustion subscale of the Oldenburg Burnout Inventory (OLBI) more strongly correlated with the depression subscale of the Hospital Anxiety and Depression Scale than with the OLBI's own disengagement subscale. These structural inconsistencies should be carefully examined by burnout researchers in the future.

Our ancillary analyses including reduced personal accomplishment permitted us to confirm the divergent character of this dimension within the burnout syndrome (Hakanen \& Schaufeli, 2012; Schaufeli \& Taris, 2005). Reduced personal accomplishment only shared $12 \%$ of its variance with emotional exhaustion and $16 \%$ with depersonalization. Given the large sample on which the findings are based, these results are likely to offer a reliable estimate of the correlation between reduced personal accomplishment and each of the two other dimensions of burnout. These findings suggest that reduced personal accomplishment is, at best, a very secondary concern in clinical interventions and prevention efforts to address burnout. 


\section{The Comorbidity Hypothesis}

It may be tempting to discuss the overlap of burnout with depression in terms of comorbidity, following the idea that burnout and depression develop in tandem (see Hakanen \& Schaufeli, 2012). However, such an approach is, in our view, untimely, given the current absence of a clear clinical distinction between burnout and depression, and given the fact that burnout is not considered a distinct pathology in international nosological classifications (see Bianchi et al., 2013). Reasoning in terms of comorbidity would be reasoning as if the hypothesis that burnout is a distinct category of psychopathology reflected established scientific consensus.

\section{Test Specificity and Definitional Adherence}

Importantly, the overlap that we observed between burnout and depression is wider than usually reported. In the only other study that examined whether burned-out individuals met $D S M-I V$ (APA, 1994) diagnostic criteria for depressive disorders (Ahola et al., 2005), about 53\% of the participants with severe burnout presented with a depressive disorder. The discrepancy between these results and ours is likely to be related to the different cutpoints that were used in the two studies (see Table 3). Whereas Ahola et al. (2005) chose a score of 3.5/6.0 to delineate "severe" burnout, we opted for a cutpoint of 5.0/6.0 to identify probable cases of burnout. It is worth underlining that an MBI mean score of 3.5/6.0 corresponds to burnout symptoms experienced between "a few times a month" and "once a week." As noted elsewhere (Bianchi et al., 2013), characterizing severe burnout on the basis of such low symptom frequencies is questionable. Indeed, according to the conceptualization of burnout on which the MBI is built, a worker in a state of burnout is supposed to be constantly overwhelmed, stressed, and exhausted (Leiter \& Maslach, 2005). The state of burnout is not a transient response to a punctual adaptive challenge, appearing and disappearing from one day to the other (Schaufeli \& Buunk, 2004). It is the end stage of a long-term process of resource depletion that leaves the individual drained and feeling like replenishment is out of reach. These key definitional elements are neglected when cutoff scores associated with low symptom frequencies are adopted to define burnout.

By contrast, a cutpoint of 5.0/6.0 is consistent with what the state of burnout is conceived to be and limits the risk of mistakenly categorizing as burned-out individuals who are only experiencing nonmorbid job stress. Supporting this analysis, in a review of preliminary attempts to define "clinical burnout" based on the MBI, Schaufeli and Enzmann (1998, p. 58) 
suggested that conservative cutoff scores are more appropriate when interested in classifying what they called "real" cases of burnout. In any case, favoring the specificity-as opposed to the sensitivity-of the sampledefining test (i.e., minimizing false-positive inclusion) is crucial in such studies to avoid erroneous conclusions about the degree of overlap between the entities of interest. In other words, the Type I error rate (the false positive rate) can here be considered a greater threat to the validity of the results than the Type II error rate (the false negative rate). All in all, the MBI cutpoint of 5 chosen in our study likely allowed a more accurate evaluation of the burnout-depression overlap than the lower thresholds used in past research. The present study thus offers a unique contribution toward the resolution of the burnout-depression controversy.

\section{Implications}

The view that burnout is distinct from depression has sometimes been accompanied by the belief that burnout is less debilitating and less of an individual problem than depression (see Schaufeli \& Enzmann, 1998, p. 187; see also Maslach et al., 2001, p. 409). This belief can discourage a worker (self-)identified as burned out from consulting a health professional and thus delay treatment (Bahlmann et al., 2013). If burnout finds its place within the depressive disorder spectrum, the risk of minimizing the need for treatment could be reduced. Furthermore, current ways of managing burnout, for instance, by recommending time off work, should be enhanced. Indeed, getting out of a depressive episode generally requires a multilevel support involving psychotherapy and/or pharmacotherapy.

\section{Limitations}

At least four limitations to the present study should be mentioned. First, a questionnaire-based provisional diagnosis is not synonymous with an interview-based psychiatric diagnosis. Although the PHQ-9 has been specifically designed from a diagnostic perspective, is directly referenced to $D S M-I V$ (APA, 1994) criteria, and displays strong psychometric properties (Andrews et al., 2007; Kroenke \& Spitzer, 2002; Kroenke et al., 2001), the structured clinical interview remains the method of preference for diagnosing depression. Second, the male/female ratio in our study was about 1:4, making it difficult to generalize findings beyond women. Third, the cross-sectional design of the study did not allow for a diachronic perspective on the phenomena of interest. Fourth, our participant pool comprised only one 
occupational group - teachers. Even if we have no reason to expect different patterns of results when examining other categories of workers, the generalization of our findings to other occupational groups should be made with caution until more research is conducted.

It might be asserted that our results are biased by the use of partly unorthodox criteria for defining burnout or by a too-conservative cutpoint for isolating cases of burnout. Our ancillary analyses contradict such a view. Indeed, when using the three subscales of the MBI, unweighted burnout scores, and a more liberal cutpoint of 4 to characterize burnout $(n=212)$, about $83 \%$ of the burned-out participants were identified as depressed (see Table 5). This proportion $(83 \%)$ is very close to the proportion that was obtained using more refined criteria (two dimensions, weighted burnout scores) and a cutpoint of 5 (90\%), and would lead to similar conclusions regarding the burnout-depression overlap. Thus, the "unorthodoxy assumption" can be reasonably rejected.

\section{CONCLUSIONS}

Evidence is growing that the overlap of burnout and depression has been underestimated (Bianchi et al., 2013). The atypical subtype of depression may play an important role in this equation. As eloquently summarized by Cox, Tisserand, and Taris (2005), "current practice in the majority of burnout research is to study variations in burnout in workers who are, in fact, not burned out" (p. 190). This tendency may have been particularly misleading with regard to the burnout-depression distinction. Indeed, it is not surprising that burnout may appear as distinct from depression if cases of depression are sought among noncases of burnout. It is well known that generalizing findings associated with subclinical forms of a syndrome to its clinical forms can be misguided (Ingram \& Siegle, 2009). Even if one conceptualizes burnout dimensionally, generalizing findings bearing on mild or moderate burnout to severe burnout is similarly unwarranted (Bianchi et al., 2013).

A rigorous comparison of burnout and depression requires determining (a) how burnout as a process differs from a process of depression, and (b) how burnout as a state (i.e., as the end stage of the aforementioned process) differs from a state of depression (e.g., a depressive episode). Crucially, given the magnitude of the overlap with depression at the high end of the burnout continuum, so-called clinical burnout (see Schaufeli \& Enzmann, 1998, p. 74) is likely to be a form of depression (Kahn, 2008; Rydmark et al., 2006; see also Hallsten, 1993). Following this line of reasoning, considering burnout as a distinct nosological entity would be mistaken. More research is needed to either confirm or disconfirm this hypothesis. 
A great deal of clinical research shows that depression is treatable (Butler, Chapman, Forman, \& Beck, 2006; Gotlib \& Hammen, 2009). To our knowledge, although burnout is often treated with antidepressants in practice, there is not a substantial literature on clinical trials designed to assess the efficacy of treatments for burnout. If burnout turns out to be indistinct from depression, then the clinical research on treatments for depression offers hope for helping working people suffering from "burnout."

\section{REFERENCES}

Ahola, K., Honkonen, T., Isometsä, E., Kalimo, R., Nykyri, E., Aromaa, A., \& Lönnqvist, J. (2005). The relationship between job-related burnout and depressive disorders-Results from the Finnish Health 2000 Study. Journal of Affective Disorders, 88, 55-62. doi: 10.1016/j.jad.2005.06.004

Ahola, K., Honkonen, T., Virtanen, M., Kivimäki, M., Isometsä, E., Aromaa, A., \& Lönnqvist, J. (2007). Interventions in relation to occupational burnout: The population-based health 2000 study. Journal of Occupational and Environmental Medicine, 49, 943-952. doi: 10.1097/JOM.0b013e31813736e3

American Psychiatric Association. (1994). Diagnostic and statistical manual of mental disorders (4th ed.). Washington, DC: Author.

Andrews, G., Brugha, T., Thase, M. E., Duffy, F. F., Rucci, P., \& Slade, T. (2007). Dimensionality and the category of major depressive episode. International Journal of Methods in Psychiatric Research, 16(Suppl. 1), S41-S51. doi:10.1002/mpr.216

Bahlmann, J., Angermeyer, M. C., \& Schomerus, G. (2013). "Burnout" statt "Depression" eine Strategie zur Vermeidung von Stigma? [Calling it "burnout" instead of "depression" - a strategy to avoid stigma?]. Psychiatrische Praxis, 40, 78-82. doi:10.1055/s-00321332891

Bianchi, R., Boffy, C., Hingray, C., Truchot, D., \& Laurent, E. (2013). Comparative symptomatology of burnout and depression. Journal of Health Psychology, 18, 782-787. doi:10.1177/1359105313481079

Brenninkmeijer, V., \& van Yperen, N. W. (2003). How to conduct research on burnout: Advantages and disadvantages of a unidimensional approach in burnout research. Occupational and Environmental Medicine, 60(Suppl. 1), i16-i20. doi:10.1136/oem.60 .suppl_1.i16

Brenninkmeyer, V., van Yperen, N. W., \& Buunk, B. P. (2001). Burnout and depression are not identical twins: Is decline of superiority a distinguishing feature? Personality and Individual Differences, 30, 873-880. doi:10.1016/S0191-8869(00)00079-9

Butler, A. C., Chapman, J. E., Forman, E. M., \& Beck, A. T. (2006). The empirical status of cognitive-behavioral therapy: A review of meta-analyses. Clinical Psychology Review, 26, 17-31. doi:10.1016/j.cpr.2005.07.003

Cox, T., Tisserand, M., \& Taris, T. (2005). Editorial: The conceptualization and measurement of burnout: Questions and directions. Work \& Stress, 19, 187-191. doi:10.1080/ 02678370500387109

Freudenberger, H. J. (1974). Staff burnout. Journal of Social Issues, 30, 159-165. doi:10.1111/ j.1540-4560.1974.tb00706.x

Gilbert, P. (2006). Evolution and depression: Issues and implications. Psychological Medicine, 36, 287-297. doi:10.1017/S0033291705006112

Gold, P. W., \& Chrousos, G. P. (2002). Organization of the stress system and its dysregulation in melancholic and atypical depression: High vs low CRH/NE states. Molecular Psychiatry, 7, 254-275. doi:10.1038/sj.mp.4001032 
Gosling, S. D., Vazire, S., Srivastava, S., \& John, O. P. (2004). Should we trust web-based studies? A comparative analysis of six preconceptions about Internet questionnaires. American Psychologist, 59, 93-104. doi:10.1037/0003-066X.59.2.93

Gotlib, I. H., \& Hammen, C. L. (2009). Handbook of depression (2nd ed.). New York, NY: Guilford Press.

Hakanen, J. J., \& Schaufeli, W. B. (2012). Do burnout and work engagement predict depressive symptoms and life satisfaction? A three-wave seven-year prospective study. Journal of Affective Disorders, 141, 415-424. doi:10.1016/j.jad.2012.02.043

Hallsten, L. (1993). Burning out: A framework. In W. B. Schaufeli, C. Maslach, \& T. Marek (Eds.), Professional burnout: Recent developments in theory and research (pp. 95-113). London, UK: Taylor \& Francis.

Hätinen, M., Kinnunen, U., Pekkonen, M., \& Kalimo, R. (2007). Comparing two burnout interventions: Perceived job control mediates decreases in burnout. International Journal of Stress Management, 14, 227-248. doi:10.1037/1072-5245.14.3.227

Iacovides, A., Fountoulakis, K. N., Kaprinis, S., \& Kaprinis, G. (2003). The relationship between job stress, burnout and clinical depression. Journal of Affective Disorders, 75, 209-221. doi:10.1016/S0165-0327(02)00101-5

Ingram, R. E., \& Siegle, G. J. (2009). Methodological issues in the study of depression. In I. H. Gotlib \& C. L. Hammen (Eds.), Handbook of depression (2nd ed., pp. 69-92). New York, NY: Guilford Press.

Jones, S. R., Fernyhough, C., de-Wit, L., \& Meins, E. (2008). A message in the medium? Assessing the reliability of psychopathology e-questionnaires. Personality and Individual Differences, 44, 349-359. doi:10.1016/j.paid.2007.08.014

Kahn, J. P. (2008). Diagnosis and referral of workplace depression. Journal of Occupational and Environmental Medicine, 50, 396-400. doi:10.1097/JOM.0b013e31816c0043

Kristensen, T. S. (1995). The demand-control-support model: Methodological challenges for future research. Stress Medicine, 11, 17-26. doi:10.1002/smi.2460110104

Kristensen, T. S., Borritz, M., Villadsen, E., \& Christensen, K. B. (2005). The Copenhagen Burnout Inventory: A new tool for the assessment of burnout. Work \& Stress, 19, 192-207. doi:10.1080/02678370500297720

Kroenke, K., \& Spitzer, R. L. (2002). The PHQ-9: A new depression diagnostic and severity measure. Psychiatric Annals, 32, 509-515. doi:10.3928/0048-5713-20020901-06

Kroenke, K., Spitzer, R. L., \& Williams, J. B. W. (2001). The PHQ-9: Validity of a brief depression severity measure. Journal of General Internal Medicine, 16, 606-613. doi: 10.1046/j.1525-1497.2001.016009606.x

Leiter, M. P., \& Maslach, C. (2005). Banishing burnout: Six strategies for improving your relationship with work. San Francisco, CA: Jossey-Bass.

Maslach, C., Jackson, S. E., \& Leiter, M. P. (1996). Maslach Burnout Inventory manual (3rd ed.). Palo Alto, CA: Consulting Psychologists Press.

Maslach, C., Schaufeli, W. B., \& Leiter, M. P. (2001). Job burnout. Annual Review of Psychology, 52, 397-422. doi:10.1146/annurev.psych.52.1.397

McEwen, B. S. (2004). Protection and damage from acute and chronic stress: Allostasis and allostatic overload and relevance to the pathophysiology of psychiatric disorders. Annals of the New York Academy of Sciences, 1032, 1-7. doi:10.1196/annals.1314.001

Nierenberg, A. A., Alpert, J. E., Pava, J., Rosenbaum, J. F., \& Fava, M. (1998). Course and treatment of atypical depression. Journal of Clinical Psychiatry, 59(Suppl. 18), 5-9.

Peterson, C., Maier, S. F., \& Seligman, M. E. P. (1993). Learned helplessness: A theory for the age of personal control. New York, NY: Oxford University Press.

Peterson, U., Demerouti, E., Bergström, G., Samuelsson, M., Åsberg, M., \& Nygren, Å. (2008). Burnout and physical and mental health among Swedish healthcare workers. Journal of Advanced Nursing, 62, 84-95. doi:10.1111/j.1365-2648.2007.04580.x

Quitkin, F. M. (2002). Depression with atypical features: Diagnostic validity, prevalence, and treatment. The Primary Care Companion to the Journal of Clinical Psychiatry, 4, 94-99. doi:10.4088/PCC.v04n0302

Ritter, P., Lorig, K., Laurent, D., \& Matthews, K. (2004). Internet versus mailed questionnaires: A randomized comparison. Journal of Medical Internet Research, 6, e29. doi:10.2196/ jmir.6.3.e29 
Rössler, W., Hengartner, M., Ajdacic-Gross, V., \& Angst, J. (in press). Predictors of burnout: Results from a prospective community study. European Archives of Psychiatry and Clinical Neuroscience. Advance online publication.

Rydmark, I., Wahlberg, K., Ghatan, P. H., Modell, S., Nygren, Å., Ingvar, M., . . . Heilig, M. (2006). Neuroendocrine, cognitive and structural imaging characteristics of women on longterm sickleave with job stress-induced depression. Biological Psychiatry, 60, 867873. doi:10.1016/j.biopsych.2006.04.029

Sapolsky, R. M. (2004). Why zebras don't get ulcers (3rd ed.). New York, NY: Holt Paperbacks.

Schaufeli, W. B. (2003). Past performance and future perspectives of burnout research. South African Journal of Industrial Psychology, 29, 1-15.

Schaufeli, W. B., \& Buunk, B. P. (2004). Burnout: An overview of 25 years of research and theorizing. In M. J. Schabracq, J. A. M. Winnubst, \& C. L. Cooper (Eds.), The handbook of work and health psychology (2nd ed.; pp. 383-425). Chichester, UK: Wiley. doi: 10.1002/0470013400.ch19

Schaufeli, W. B., \& Enzmann, D. (1998). The burnout companion to study and practice: A critical analysis. London, UK: Taylor \& Francis.

Schaufeli, W. B., \& Taris, T. W. (2005). The conceptualization and measurement of burnout: Common ground and worlds apart. Work \& Stress, 19, 256-262. doi:10.1080/ 02678370500385913

Shirom, A. (2005). Reflections on the study of burnout. Work \& Stress, 19, 263-270. doi: $10.1080 / 02678370500376649$

Shirom, A., \& Melamed, S. (2006). A comparison of the construct validity of two burnout measures in two groups of professionals. International Journal of Stress Management, 13, 176-200. doi:10.1037/1072-5245.13.2.176

Sokero, T. P., Melartin, T. K., Rytsälä, H. J., Leskelä, U. S., Lestelä-Mielonen, P. S., \& Isometsä, E. T. (2003). Suicidal ideation and attempts among psychiatric patients with major depressive disorder. Journal of Clinical Psychiatry, 64, 1094-1100. doi:10.4088/ JCP.v64n0916

Taris, T. W. (2006). Bricks without clay: On urban myths in occupational health psychology. Work \& Stress, 20, 99-104. doi:10.1080/02678370600893410

Tennant, C. (2001). Work-related stress and depressive disorders. Journal of Psychosomatic Research, 51, 697-704. doi:10.1016/S0022-3999(01)00255-0

Tops, M., Boksem, M. A. S., Wijers, A. A., van Duinen, H., Den Boer, J. A., Meijman, T. F., \& Korf, J. (2007). The psychobiology of burnout: Are there two different syndromes? Neuropsychobiology, 55, 143-150. doi:10.1159/000106056

Tops, M., Riese, H., Oldehinkel, A. J., Rijsdijk, F. V., \& Ormel, J. (2008). Rejection sensitivity relates to hypocortisolism and depressed mood state in young women. Psychoneuroendocrinology, 33, 551-559. doi:10.1016/j.psyneuen.2008.01.011

Winwood, P. C., \& Winefield, A. H. (2004). Comparing two measures of burnout among dentists in Australia. International Journal of Stress Management, 11, 282-289. doi: $10.1037 / 1072-5245.11 .3 .282$

Received January 18, 2014

Revision received June 30, 2014

Accepted August 8, 2014 